\title{
Work In Progress - Building the Survey of Engineering Ethical Development (SEED) Instrument
}

\author{
Janel Sutkus, Donald Carpenter, Cynthia Finelli, and Trevor Harding \\ jsutkus@umich.edu, carpenter@ltu.edu, cfinelli@umich.edu, tharding@calpoly.edu
}

\begin{abstract}
When developing surveys, researchers can readily identify the concepts they intend to study, but how do they create individual survey items that will most accurately measure those concepts? Here we describe the first year of a four-year NSF project in which the $\mathrm{E}^{3}$ Team (Exploring Ethical Decision Making in Engineering) prepared to develop a national survey of the curricular and cocurricular activities, events, and experiences affecting the ethical development of engineering undergraduates. As this survey is likely to be the most comprehensive assessment of ethical development - both in content and scope - ever administered to engineering undergraduates, it is critical the development process includes rigorous and thorough educational research methods. By using such methods, we greatly increase the probability our survey instrument will appropriately measure the determinants of ethical behavior in engineering undergraduates.
\end{abstract}

Index Terms - ethics, focus groups and interviews, qualitative research, survey development

\section{INTRODUCTION}

The goal of the SEED study is to enact educational reform by identifying the factors which positively affect the ethical development of engineering undergraduates, and then disseminating those results through broad channels. The first year of the project is preparation for developing a national online survey which will measure the curricular and cocurricular activities, events, and experiences affecting ethical development. We employ qualitative methods - particularly focus groups and interviews - to inform the survey development. Sixteen institutions agreed to partner with us and designate an on-campus liaison - four each from the Carnegie classifications of Baccalaureate and specialty institutions (combined), Master's institutions, high research institutions, and very high research institutions. Two additional institutions agreed to be testing sites for the focus groups and interviews and one institution agreed to be a testing site for the online survey.

\section{UNDERSTANDING FOCUS GROUPS AND INTERVIEWS}

In order to ensure our survey would accurately measure our intended concepts, it was important we first understood the

978-1-4244-1970-8/08/\$25.00 @2008 IEEE use, purposes, benefits, and risks of the qualitative methods used in survey development. ${ }^{1}$

The first purpose of a focus group is to capture all domains (the broadest category being investigated) to be measured in the survey [2,3]. In the SEED study, the predetermined domains are curricular and co-curricular events, activities, and experiences; student characteristics; and institutional culture. The benefit of this method is the ability to gather a wide range of perspectives in a short amount of time and therefore gain a complete picture of participants' thinking. This is critical for survey development as it reduces potential for omitting relevant variables, which can bias the coefficients of the included variables and result in unfounded conclusions. Although it is possible to determine all domains in advance, it is important to be open to the possibility of emergent domains.

The second purpose of a focus group is to determine all of the dimensions comprising each domain [2,3]. The predetermined dimensions within the SEED co-curricular domain, for example, were service learning, Greek life, athletics, volunteerism, and professional student engineering organizations. Here the benefits are the reduction of invalid survey data by ensuring questions fully cover the domain content and the reduction of omitted variable problems. Again, it is possible to predetermine all dimensions.

The third purpose of a focus group is to develop item wordings that effectively convey our intent to the respondents $[2,3]$. This improves survey validity by finding wordings appropriate to the widest range of participants and by minimizing differences in how participants interpret questions.

The risk in using focus groups can occur during analysis if the responses are used to determine the research rather than to guide it by letting isolated focus group remarks push the research into a direction not supported by the broader data [2].

\section{Creating the Protocols}

In order to gain both teacher and learner perspectives on the determinants of ethical development, we decided to conduct focus groups with engineering students and faculty and to interview academic affairs and student affairs administrators at each partner institution. The interviewees were chosen based on their knowledge of ethics and ethics instruction within the engineering program. Although they were often members of the college of engineering, several were not, especially student affairs professionals. In order to keep the student focus groups at 90 minutes, we separated the domains and dimensions into

\footnotetext{
${ }^{1}$ The use, purposes, benefits, and risks of interviews are very similar to those of focus groups; therefore, we used the same rationale to create interview protocols as we did for focus group protocols.
}

October 22 - 25, 2008, Saratoga Springs, NY

$3^{\text {th }}$ ASEE/IEEE Frontiers in Education Conference 
two student protocols. The first includes questions about curricular and co-curricular experiences; the second includes questions on how students approach ethical decision-making. Both include questions about institutional culture. The faculty and administrator protocols are very similar to the first student protocol but are adjusted to fit the participant's role, i.e. more questions about co-curricular activities for student affairs professionals and more questions about curricular activities for faculty and academic affairs administrators.

\section{Testing the Protocols}

In the fall of 2007, following Institutional Review Board approval at our home institutions and all visit sites, we tested our protocols at the two pilot institutions. All visits were conducted by two researchers. The team's research assistant moderated the focus groups and one of the three principal investigators conducted the interviews. All participants signed a consent form agreeing to be audio-recorded and to allow their comments to be published. The team member not conducting the session took notes, and we debriefed each session by audio-recording our impressions.

We made no changes to the interview protocols and two changes to the student and faculty protocols. First, when asked about the activities affecting ethical development, participants related them only to ethical knowledge and ethical behavior, omitting ethical reasoning ability. Therefore, we subsequently asked participants to comment specifically on activities affecting ethical reasoning ability. Second, although we informed participants our definition of ethical development focuses on professional engineering ethics, their responses centered on academic ethics, such as cheating and plagiarism. We added a statement informing participants we would speak about engineering ethics and academic ethics, asking them to speak first about engineering ethics, and then asking them to speak about academic ethics. This ensured our data was not limited to information about cheating behaviors.

\section{CONDUCTING THE FOCUS GROUPS AND INTERVIEWS}

We selected two institutions from each of the four Carnegie categories and visited them during the 2007-2008 academic year, conducting one of each student protocol in each pair within the same Carnegie category. The two pilot visits and eight partner visits resulted in 20 administrator interviews and focus groups with 66 students and 59 faculty members. We employed a random recruitment process for the students and asked the on-campus liaison to select faculty and administrators either involved in ethics education or with knowledge of how ethics is included within the curriculum. We tracked the participants' demographics characteristics through a brief anonymous survey. Student participants reflect the demographics of engineering students nationwide. Most are white males who are exclusively majoring in an engineering discipline [1]. Faculty participants are mostly tenured white males with at least seven years of teaching experience.

\section{ANALYZING AND SUMmarizing THE DATA}

We coded three types of transcript data: 1) the types of activities affecting ethical development, for example, ethical case studies; 2) the manner in which those activities were conducted, for example, a case study presented by an actual participant in the case who asked students to reflect upon it and create their own ethically defensible solution; and 3) cultural aspects of the institution, for example, a mandatory service-learning program. Transcript analysis revealed no new domains, but several additional dimensions emerged, including membership in student government, design teams, and organizations which allocate student activity fees to student groups. In addition, leadership emerged as a dimension, as students made a very clear distinction between the ethical situations faced by group members and those faced by appointed or elected leaders. All dimensions were distilled into a list of potential survey items which will be expanded after visits to the remaining partner institutions.

We used the data related to institutional culture to develop a cultural summary of each institution. We separated the data into categories such as "institutional focus on ethics," "barriers to ethical behavior," "student/faculty relationships," and "student demographics." As these summaries will be further synthesized in order to create context when reporting survey results to each institution, we did not limit the analysis to cultural aspects which affect ethical development, but coded any comments related to institutional culture.

\section{NeXT STEPS}

We will visit the remaining eight partner institutions in 20082009 and are currently developing a survey outline and a protocol for online administration. Remaining project tasks include developing, testing, and administering the survey; analyzing the data and identifying factors which affect ethical development; and disseminating the results. Survey administration will occur in 2009-2010.

\section{ACKNOWLEDGMENT}

This material is based upon work supported by the National Science Foundation under Grant No. 0647532.

\section{REFERENCES}

1. Gibbons, M., "Engineering by the numbers." American Society for Engineering Education, 2007.

2. Morgan, D., Focus groups as qualitative research, 1997.

3. O'Brien, K., "Improving survey questionnaires through focus groups,"

Successful focus groups: Advancing the state of the art, pp. 105-117, 1993.

\section{AUTHOR INFORMATION}

Janel Sutkus, Director of Institutional Research and Analysis, Carnegie Mellon University

Donald Carpenter, Associate Professor, Civil Engineering, Lawrence Technological University

Cynthia Finelli, Director, Center for Research on Learning and Teaching North, University of Michigan

Trevor Harding, Associate Professor, Materials Engineering, California Polytechnic State University 